\title{
Cost-effectiveness analysis of a multifactorial fall prevention intervention in older home care clients at risk for falling
}

\author{
Wanrudee Isaranuwatchai ${ }^{1,2^{*}}$ (D), Johnna Perdrizet ${ }^{1}$, Maureen Markle-Reid ${ }^{3}$ and Jeffrey S. Hoch ${ }^{1,2,4}$
}

\begin{abstract}
Background: Falls among older adults can cause serious morbidity and pose economic burdens on society. Older age is a known risk factor for falls and age has been shown to influence the effectiveness of fall prevention programs. To our knowledge, no studies have explicitly investigated whether cost-effectiveness of a multifactorial fall prevention intervention (the intervention) is influenced by age. This economic evaluation explores: 1) the cost-effectiveness of a multifactorial fall prevention intervention compared to usual care for community-dwelling adults $\geq 75$ years at risk of falling in Canada; and 2) the influence of age on the cost-effectiveness of the intervention.
\end{abstract}

Methods: Net benefit regression was used to examine the cost-effectiveness of the intervention with willingnessto-pay values ranging from $\$ 0-\$ 50,000$. Effects were measured as change in the number of falls, from baseline to 6-month follow-up. Costs were measured using a societal perspective. The cost-effectiveness analysis was conducted for both the total sample and by age subgroups (75-84 and 85+ years).

Results: For the total sample, the intervention was not economically attractive. However, the intervention was cost-effective at higher willingness-to-pay (WTP) $(\geq \$ 25,000)$ for adults $75-84$ years and at lower WTP $(<\$ 5,000)$ for adults $85+$ years.

Conclusions: The cost-effectiveness of the intervention depends on age and decision makers' WTP to prevent falls. Understanding the influence of age on the cost-effectiveness of an intervention may help to target resources to those who benefit most.

Trial registration: Retrospectively registered. Clinicaltrials.gov identifier: NCT00463658 (18 April 2007).

Keywords: Cost-effectiveness analysis, Fall prevention, Age, Older adults, Multifactorial intervention

\section{Background}

Falls among older community-dwelling adults cause significant problems, and evidence suggests that most falls are predictable and preventable [1-5]. Falls are the leading cause of injury-related hospitalization for seniors; and the economic costs of falls are likely greater than decision-makers expect $[6,7]$. In general, falls result

\footnotetext{
* Correspondence: IsaranuwatcW@smh.ca

${ }^{1}$ Centre for Excellence in Economic Analysis Research, Li Ka Shing Knowledge Institute, St. Michael's Hospital, 30 Bond Street, Toronto, ON M5B 1W8, Canada

${ }^{2}$ Institute of Health Policy, Management and Evaluation, University of Toronto, 155 College St, Toronto, ON M5T 3M6, Canada

Full list of author information is available at the end of the article
}

from the interaction of multiple risk factors, many of which are preventable [8-11]. Fall prevention strategies incorporating multifactorial and interprofessional approaches, aimed at multiple risk factors contributing to falls, might be the most successful [12]. Studies have shown that multifactorial programs are as effective at reducing falls as single intervention programs [13].

Although the goals of a fall prevention program are to improve health outcomes including reducing fall risk factors, preventing falls and fall-related use of health services, and maintaining quality of life, cost-effectiveness is also a critical factor. Decision- and policy-makers often have an implicit monetary value that they are willing to spend in order to produce a particular health outcome 
(e.g., prevent a fall), referred to as willingness-to-pay (WTP). An intervention may be effective at reducing falls, but if its costs are prohibitively high, it may not be a practical option for implementation given the WTP. To adequately inform policy- and decision-makers, both effectiveness and cost-effectiveness of interventions (including the suitability of intervention to individuals) need to be assessed.

Many fall prevention interventions for communitydwelling older adults have proven cost-effectiveness [3, 14-22]. However, similar interventions demonstrate conflicting cost-effectiveness results in different populations and settings [20, 23-29]. For example, some studies reported that multifactorial programs are an economically attractive option $[17,20,22-26$, 29] for reducing falls in community-dwelling older adults, whereas others studies reported the opposite $[14,15,17]$. These data suggest that multifactorial programs were not cost-effective and subsequently performed subgroup analysis, found the program was cost-effective for specific geographic regions or for particular community-dwelling subgroups [22, 24]. Therefore, the cost-effectiveness of a multifactorial program can vary depending on characteristics of community-dwelling older adults.

It is well established that fall incidence rates and related injuries steadily increase as a function of age [4]. Given that age is a significant risk factor for falls and fall-related injuries, multifactorial approaches could be more effective, and potentially cost-effective, if age was a factor considered in fall prevention programs. MarkleReid et al. (2010a) conducted a randomized controlled trial (RCT) of a multifactorial intervention among community-dwelling older adults at risk of falling and found that compared to usual home care, the intervention was effective in reducing falls in 75-84 year old adults but not for $85+$ year old adults. These findings are consistent with the idea that age is associated with the effectiveness of an intervention. Moreover, Wu et al. (2010) found that a multifactorial program was more cost-effective for younger (65-74 years) compared to older ( $\geq 75$ years) adults [17]. Consequently, age has been shown to be a factor influencing the cost-effectiveness of a multifactorial fall prevention intervention [9]. However, the model by Wu et al. (2010) did not examine the variability of cost-effectiveness among older adults ( $\geq 75$ years), who are at highest risk of falls.

Using cost and effectiveness data from Markle-Reid et al. (2010b), we conducted a secondary data analysis: 1) to determine the cost-effectiveness of a multifactorial fall prevention intervention compared to usual home care for community-dwelling older adults ( $\geq 75$ years), and at risk of falling; and 2) to examine the influence of age on the cost-effectiveness of the intervention.

\section{Methods}

\section{Study design}

A cost-effectiveness analysis of a multifactorial and interprofessional fall prevention intervention (the intervention) was performed using cost and effectiveness RCT data from Markle-Reid et al. (2010) [30]. A total of 109 participants were randomly assigned to the intervention or usual home care services (usual care). The total analytical sample included 92 participants that completed the 6-month follow-up. Two age subgroups were explored: young-old (75-84 years) and old-old (85+ years).

\section{Setting and participants}

Participants were community-dwelling older adults ( $\geq 75$ years), referred to and eligible for personal support services through a Community Care Access Centre (CCAC) in Southern Ontario, mentally competent, and English-speaking. Individuals were classified as being at high-risk for falls if they answered "yes" to any of the following questions: 1) have you fallen in the past 12 months; 2) do you have a fear of falling; or 3) are you unsteady on your feet $[9,31]$ ?

\section{Intervention}

Usual care participants received home care services arranged by the CCAC care coordinator, which included follow-up assessments for in-home health services eligibility; arranging professional (i.e., nursing, occupational therapy, physiotherapy, social work, speech-language pathology, and nutrition) and non-professional services (i.e., personal support services and homemaking services); providing information and referral to community agencies; and monitoring care through in-home assessments. The intervention group received usual care, plus monthly in-home visits by an interprofessional team (CCAC case manager, registered nurse, occupational therapist, physiotherapist, and registered dietitian), with specialized training in the area of fall prevention. The interprofessional team's goal was to prevent falls and fall-related injuries, enhance health and quality of life, and reduce use of health care services. Activities included: 1) conducting routine systematic assessments using standardized screening tools that identified risk factors for falls and poor health; 2) managing modifiable risk factors; 3) providing support; and 4) educating clients about fall prevention. The team met monthly to develop an interprofessional plan of care, and tailored the frequency and timing of the home visits to meet individual client needs. A detailed description of the intervention is described elsewhere $[9,30]$.

\section{Variables and measures}

The outcome was the number of falls at six-months, measured by self-report. A fall was defined as unintentionally 
coming to rest on the ground or floor. Participants kept a calendar to record daily fall status. Interviewers blinded to treatment assignment telephoned participants monthly to obtain additional information on fall incidents recorded, using the Falls Surveillance Report, created by the research team [30].

The costs of health service utilization were measured using the Health and Social Services Utilization Inventory (HSSUI), which assesses costs from a societal perspective and has established reliability and validity [32-34]. The total cost per person was calculated by multiplying the number of units of service (quantity) and unit cost (price). The HSSUI consists of six direct health care service categories: 1) primary care; 2) emergency department and specialists; 3 ) hospital days; 4) other health and social care professionals; 5) prescription medications; and 6) lab services. Data collection was restricted to the reliable duration of recall: six months for hospitalization, two weeks for physician visits, and two days for prescription medication [32]. Questions to assess participant out-of-pocket costs are also included in the HSSUI, and described elsewhere [32]. Costs were reported in 2006 Canadian dollars (CAD). Cost and effect variables were defined as the change in falls or costs from baseline to follow-up. Baseline costs and effects were recorded for six-months before randomization. Follow-up costs and effects were recorded for six months after randomization. Potential confounders were identified from the literature $[1,5,9,30]$, including age, sex, fear of falling, and previous fall in the last six months.

\section{Statistical analysis}

Analysis was performed using Stata (version 14, Stata Corp, Texas, USA). Student's t-test was used for continuous variables and Chi-square test for categorical variables to compare characteristics between the intervention and usual care groups. We conducted two analyses: 1) for the total sample; and 2) by age subgroups (young-old defined as 75-84 year old adults and old-old defined as $85+$ year old adults). The total sample analysis included all covariates, but the subgroup analyses omitted the age variable. Cost-effectiveness analysis was conducted using a net benefit regression (NBR) framework [35]. Net benefit (NB) values for each participant were calculated for six WTP values, varying from 0 to 50,000 CAD [35]. The WTP quantifies the value decision makers would be willing to pay to prevent one fall [36]. The NBR approach used a linear regression framework to facilitate the cost-effectiveness analysis. As each participant has a specific NB value for each WTP, we created a separate regression model for each WTP with a $\mathrm{NB}$ value as the dependent variable; the intervention variable was the primary independent variable, and the covariates were age, sex, fear of falling, and previous history of falling. From the regression findings, the coefficient estimate on the intervention variable represented the incremental net benefit (INB), given the specific WTP value used for that regression. A positive INB (INB >0) indicated that the intervention was cost-effective; whereas a negative INB $($ INB $<0)$ demonstrated the opposite. The INB of the intervention compared to usual care was calculated for the total sample and, subsequently, by age subgroups. Cost-effectiveness acceptability curves (CEACs) were created for the total sample and age subgroups. The CEAC illustrates uncertainty and is a form of sensitivity analysis [37]. Each CEAC indicated the probability that the intervention was cost-effective compared to usual care for a given WTP value [38].

\section{Results}

Table 1 compares participant characteristics between the intervention and usual care group for the 92 participants who completed the 6-month follow-up, young-old $(n=49)$, and old-old $(n=43)$. The number of falls decreased in both groups, from baseline to 6-month followup; however, there was no difference in the change in the mean number of falls, from baseline to 6-month followup, for both the intervention and usual care group (mean change in falls \pm standard deviation (SD): $0.3 \pm 2.6$ versus $0.3 \pm 3.3$, respectively). In the young-old subgroup, a greater reduction in the number of falls was found for the intervention (mean change in falls \pm SD: $0.1 \pm 1.7$ ) compared to usual care (mean change in falls \pm SD: $-0.8 \pm 2.4$ ). In addition, there was a difference in the mean cost at baseline between the intervention (mean change in $\mathrm{CAD} \pm$ SD: $17,533 \pm 18,335$ ) and usual care groups (mean change in $\mathrm{CAD} \pm \mathrm{SD}: 37,615 \pm 32,833), p<0.05$. The change in mean cost from baseline to 6-month follow-up between the intervention and the usual care group was also different for the young-old group, $p<0.05$ (mean change in $\mathrm{CAD} \pm \mathrm{SD}:-12,743 \pm 17,498$ vs. mean change in $\mathrm{CAD} \pm \mathrm{SD}:-32,056 \pm 32,204)$.

\section{Cost-effectiveness}

Table 2 reports cost-effectiveness results for the total sample at multiple WTP values. All INB values for each model were negative for the total sample and became more negative at higher WTP values. For example, the INB in CAD was $-\$ 5518$ at a WTP of $\$ 1000$ CAD and $-\$ 7359$ at $\$ 25,000$ CAD. Thus, for the total sample, the multifactorial fall prevention intervention was not costeffective compared to usual care, regardless of a decision-maker's WTP to prevent falls. After stratification, for the young-old group, the intervention was costeffective for young-old with a WTP to prevent one fall of at least $\$ 25,000 \mathrm{CAD}$ to prevent falls. Conversely, for 
Table 1 Participants' characteristics for the total sample and by age subgroups

\begin{tabular}{|c|c|c|c|c|c|c|}
\hline \multirow[b]{2}{*}{ Participant characteristic } & \multicolumn{2}{|c|}{ Total sample, all ages } & \multicolumn{2}{|c|}{ Young-old group, 75-84 years } & \multicolumn{2}{|c|}{ Old-old group, 85-95 years } \\
\hline & $\begin{array}{l}\text { Intervention } \\
(n=49)\end{array}$ & $\begin{array}{l}\text { Usual care } \\
(n=43)\end{array}$ & $\begin{array}{l}\text { Intervention } \\
(n=27)\end{array}$ & $\begin{array}{l}\text { Usual care } \\
(n=22)\end{array}$ & $\begin{array}{l}\text { Intervention } \\
(n=22)\end{array}$ & $\begin{array}{l}\text { Usual care } \\
(n=21)\end{array}$ \\
\hline Baseline mean number of falls \pm SD & $-1.8 \pm 2.7$ & $-1.7 \pm 3.7$ & $-1.1 \pm 1.0$ & $-1.0 \pm 1.1$ & $-2.6 \pm 3.8$ & $-2.3 \pm 5.2$ \\
\hline Follow-up mean number of falls \pm SD & $-1.4 \pm 2.7$ & $-1.3 \pm 2.2$ & $-0.9 \pm 1.4$ & $-1.8 \pm 2.5$ & $-2.1 \pm 3.7$ & $-0.8 \pm 1.9$ \\
\hline Change in mean number of falls $\pm S D^{a}$ & $0.3 \pm 2.6$ & $0.3 \pm 3.3$ & $0.1 \pm 1.7$ & $-0.8 \pm 2.4$ & $0.5 \pm 3.4$ & $1.5 \pm 3.8$ \\
\hline Baseline mean cost in $C A D \pm S D$ & $20,154 \pm 21,068$ & $26,150 \pm 28,132$ & $17,533 \pm 18335^{*}$ & $37,615 \pm 32833^{*}$ & $23,372 \pm 24,056$ & $14,139 \pm 15,298$ \\
\hline Follow-up mean cost in $\mathrm{CAD} \pm \mathrm{SD}$ & $5126 \pm 3914$ & $4800 \pm 4305$ & $4789 \pm 3988$ & $5559 \pm 5359$ & $5540 \pm 3873$ & $4004 \pm 2733$ \\
\hline Change in mean cost in $C A D \pm S D^{a}$ & $-15,028 \pm 20,518$ & $-21,350 \pm 27,359$ & $-12,743 \pm 17498^{*}$ & $-32,056 \pm 32204^{*}$ & $-17,831 \pm 23,837$ & $-10,135 \pm 14,992$ \\
\hline Mean age in years \pm SD & $84.1 \pm 5.0$ & $83.2 \pm 5.1$ & $80.5 \pm 2.8$ & $78.9 \pm 2.5$ & $88.6 \pm 3.0$ & $87.7 \pm 2.7$ \\
\hline Female (\%) & $67 \%$ & $77 \%$ & $70 \%$ & $73 \%$ & $64 \%$ & $81 \%$ \\
\hline Fear of falling (\%) & $41 \%$ & $49 \%$ & $41 \%$ & $45 \%$ & $41 \%$ & $52 \%$ \\
\hline Fall in the last 6 months (\%) & $73 \%$ & $67 \%$ & $67 \%$ & $77 \%$ & $82 \%$ & $57 \%$ \\
\hline
\end{tabular}

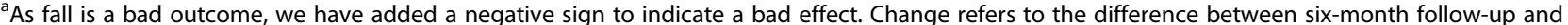
baseline. For mean change in number of falls, a high estimate implies more falls prevented. For change in mean number of falls, a positive estimate means that there were fewer falls in the "Follow-up" period than in the "Baseline" period. For change in mean cost, a lower estimate indicates fewer resources used

Intervention = multifactorial fall prevention intervention; Usual care $=$ usual home care services; $\mathrm{n}=$ number of participants; $\mathrm{SD}=\mathrm{standard}$ deviation. * denotes $p<0.05$ using Welch's $t$-test

the old-old group, the intervention was cost-effective at WTP $<\$ 5000$ CAD to prevent falls.

\section{Sensitivity analysis}

The probability that the intervention was cost effective for the total sample, young-old, and old-old subgroups is shown in Fig. 1. When age was not considered, the probability that the intervention was cost-effective ranged from $15 \%$ to $38 \%$ across WTP values (up to 50,000 CAD). However, when age was stratified by subgroups, the probability that the intervention was cost-effective was $1 \%$ in young-old and $82 \%$ in old-old at a WTP of $\$ 1000$ CAD. The opposite trend was found at higher WTP values. For example, with a WTP of 25,000 CAD to prevent a fall, the probability that the intervention was cost-effectiveness increased to $58 \%$ in young-old and decreased to $15 \%$ in the old-old group.

\section{Discussion}

Cost-effectiveness of the multifactorial fall prevention intervention depended on age and decision-makers' WTP to prevent a fall. With a specific WTP in mind, decision-makers could target those most likely to benefit from a fall prevention intervention in communitydwelling adults at risk of falling. To our knowledge, this is the first study to examine the influence of age on the cost-effectiveness of a multifactorial fall prevention intervention, and to provide the cost-effective results over a range of ages and WTP values.

Age influenced the cost-effectiveness of the intervention. With a small incremental benefit, the intervention was not economically attractive for the total sample. However, it was cost-effective for adults $85+$ years at WTP values $(<\$ 5000 \mathrm{CAD})$ and for adults $75-84$ years at higher WTP values ( $\geq \$ 25,000 \mathrm{CAD})$ to prevent a fall.

Table 2 Incremental net benefits for six willingness-to-pay values to prevent a fall for the total sample and by age subgroups

\begin{tabular}{|c|c|c|c|c|c|c|}
\hline \multirow[b]{2}{*}{ WTP } & \multicolumn{2}{|c|}{ Total sample, all ages $(n=92)^{a}$} & \multicolumn{2}{|c|}{ Young-old group, $75-84$ years $(n=49)^{b}$} & \multicolumn{2}{|c|}{ Old-old group, 85-95 years $(n=43)^{b}$} \\
\hline & $\begin{array}{l}\text { INB of intervention (CAD) } \\
{[95 \% \mathrm{CI}]}\end{array}$ & $P$ & $\begin{array}{l}\text { INB of intervention (CAD) } \\
{[95 \% \mathrm{Cl}]}\end{array}$ & $P$ & $\begin{array}{l}\text { INB of intervention (CAD) } \\
{[95 \% \mathrm{Cl}]}\end{array}$ & $P$ \\
\hline $\mathrm{WTP}=0 \mathrm{CAD}$ & $-5441[-15,622$ to 4739$]$ & 0.291 & $-20,766[-35,144$ to -6388$]$ & 0.006 & $7739[-5384$ to 20,861$]$ & 0.240 \\
\hline WTP $=1000$ CAD & $-5518[-15,825$ to 4789$]$ & 0.290 & $-19,816[-34,355$ to -5277$]$ & 0.009 & $6190[-7235$ to 19,614$]$ & 0.356 \\
\hline WTP $=5000 C A D$ & $-5825[-17,909$ to 6259$]$ & 0.341 & $-16,015[-31,981$ to -49$]$ & 0.049 & $-6[-17,845$ to 17,834$]$ & 0.999 \\
\hline$W T P=10,000$ CAD & $-6208[-22,389$ to 9972$]$ & 0.448 & $-11,264[-30,383$ to 7855$]$ & 0.241 & $-7750[-34,753$ to 19,253$]$ & 0.565 \\
\hline WTP $=25,000$ CAD & $-7359[-39,756$ to 25,039$]$ & 0.653 & $2989[-29,753$ to 35,730$]$ & 0.855 & $-30,983[-90,576$ to 28,611$]$ & 0.299 \\
\hline$W T P=50,000 C A D$ & $-9276[-71,168$ to 52,616$]$ & 0.766 & $26,743[-32,402$ to 85,888$]$ & 0.367 & $-69,704[-186,121$ to 46,713$]$ & 0.233 \\
\hline
\end{tabular}

${ }^{a}$ All six NB regression models for the full sample were adjusted for age, sex, fear of falling, and previous history of falling

${ }^{b}$ All six NB models for age subgroup analysis were adjusted for sex, fear of falling, and previous history of falling

A positive INB indicates that the intervention was cost-effective when compared to usual care

INB incremental net benefit, Intervention multifactorial fall prevention intervention; $C l$ confidence interval, $P p$-value, WTP willingness-to-pay 


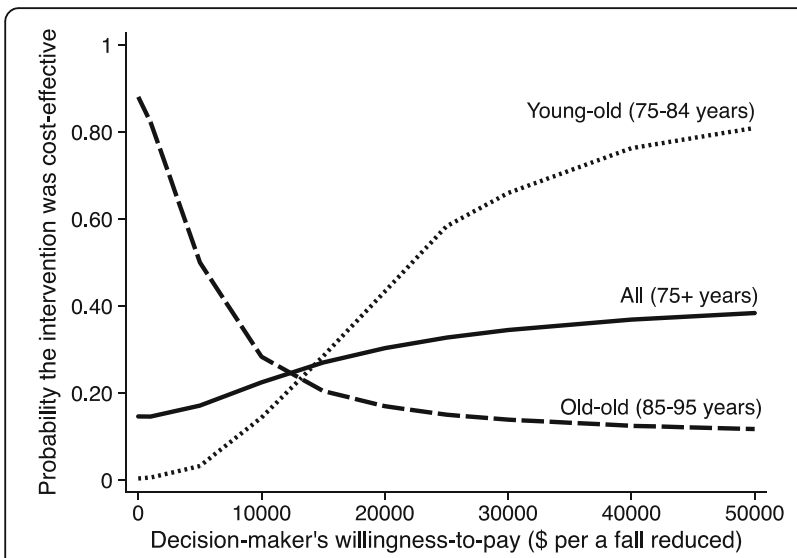

Fig. 1 A cost-effectiveness acceptability curve indicates the probability that the intervention is cost-effective compared to usual care for a given willingness-to-pay value. The $y$-axis represents the probability that the intervention was cost-effective, and the $x$-axis represents a range of willingness-to-pay values. Cost-effectiveness acceptability curves for all (75+ years), young-old (75-84 years), and old-old (85-95 years)

As the findings for different age subgroups differed, the WTP value and subsequently the intervention's costeffectiveness could differ for different subgroups as well. Recognizing the incremental benefits of the intervention, further research should explore which components of the multifactorial intervention benefit most in different age subgroups in order to optimize resource allocation and achieve value for each age subgroup.

Our study adds to the literature of the costeffectiveness of multifactorial approaches for fall prevention in community dwelling older adults reporting mixed results $[14,15,17,20,22-26,29]$. Beard et al. (2006) and Rizzo et al. (1996) reported a multifactorial program to be more cost-effective than usual care, and found cost-savings for the health care system that was attributed to the reduction in falls and fall-related injuries. Both studies incorporated an exercise component in the multifactorial intervention. However, Church et al. (2011, 2012) and Frick et al. (2010) found multifactorial approaches were dominated by several other fall prevention strategies in terms of cost-effectiveness for preventing falls, preventing hospitalizations, and more quality-adjusted life years (QALYs). Furthermore, Hendriks et al. (2008), Irvine et al. (2010), and Peeters et al. (2011) reported that the intervention was not costeffective compared to usual care, which was replicated in our results using the total sample. Potentially, these studies could have found that the intervention was costeffective for particular ages and WTP values if they were to explore age subgroups. Jenkyn et al. (2012) was the only study that used patient-level data to perform subgroup analysis, which demonstrated that a fall prevention program could be cost-effective for adults living in particular geographic regions in Ontario. Even so, conflicting findings regarding the cost-effectiveness of multifactorial programs in community dwelling adults could be due to differences in the intervention, study design, location, patient demographics, effective measures, unit costs, perspective, and timehorizon. This study reported that the cost-effectiveness of a multifactorial fall prevention intervention depended on an individual's age and decision-makers' WTP. The findings (e.g., impact of age on the cost-effectiveness of an intervention) may assist in the planning and optimizing resource allocation by directing services to those most likely to experience value.

Our study had a number of strengths. The sample from the original RCT was representative of the Canadian population at high risk of falls, since it was comprised of older adults using home services reporting fall risks [30]. The prevalence of falls in seniors with chronic needs and receiving home support services was about $70 \%[9,30]$, which greatly exceeded the $30 \%$ fall rate among the general population of community-dwelling seniors reported in the literature [39-42]. The cost-effectiveness analysis used NBR, which allowed for: [1] controlling imbalances between intervention and usual care baseline characteristics remaining after randomization; [2] exploring subgroup analysis; [3] checking modeling assumptions; and [4] avoiding pitfalls associated with reporting negative incremental cost-effectiveness ratios. Moreover, CEACs conveyed uncertainty about the cost-effectiveness of the intervention [43].

Several limitations should be noted. The sample size was small $(n=92)$; nonetheless, the data came from a well-conducted RCT $[9,30]$. Furthermore, the number of falls might have been underreported; since older people may fear loss of independent lifestyle and associated stigma of aging [44]. Nevertheless, given that study groups were randomized, underreporting should have been similar across groups. The outcome was the reduction in falls, which limited direct comparisons to studies using similar but slightly different outcomes (e.g., number of falls during the study). However, our outcome was appropriate since it took into account previous fall history and was based on its relevance to clinical practice. There were a few statistical limitations when examining the influence of age. By splitting the continuous age variable into subgroups for stratification, we lost precision in cost-effectiveness results. However, policy decisions are often based on artificial age groupings; thus, stratified results can be easily used by decision-makers.

\section{Conclusions}

The multifactorial fall prevention intervention could be economically attractive depending on age and decisionmakers' WTP to prevent falls. The study contributed to the literature regarding the effect of age on the cost- 
effectiveness of multifactorial interventions; the intervention was cost-effective in certain contexts. Understanding the influence of age on the cost-effectiveness of an intervention may help to target resources more effectively to those most likely to benefit.

\section{Abbreviations}

CAD: Canadian dollars; CCAC: Community Care Access Centre; CEACs: Cost-effectiveness acceptability curves; HSSUI: Health and Social Services Utilization Inventory; INB: Incremental net benefit; NB: Net benefit; NBR: Net benefit regression; QALYs: Quality-adjusted life years; RCT: Randomized controlled trial; SD: Standard deviation; WTP: Willingness-to-pay

\section{Acknowledgements}

This research was undertaken, in part, thanks to funding from the Canada Research Chairs Program, through Dr. Markle-Reid's Chair in Aging, Chronic Disease and Health Promotion Interventions.

\section{Funding}

This work was supported by the following agencies for funding this project from 2005 to 2008: Canadian Patient Safety Institute [grant number RFAAA0506164]; Community Care Access Centre of Halton; McMaster University System-Linked Research Unit on Health and Social Services Utilization; and Ontario Ministry of Health and Long-Term Care.

\section{Availability of data and materials}

The datasets used and/or analyzed during the current study are not publicly available because we did not request consent from the participants to have this data published online, and it was not in our approved ethics application.

\section{Author's contributions}

WI contributed to the design of the analysis, conducted the analysis, and drafted the manuscript. JP facilitated the analysis and reviewed the manuscript. MMR contributed to the original study design including data collection, and reviewed the manuscript. JH contributed to the design of the analysis and reviewed the manuscript. All authors have read and approved the manuscript.

\section{Ethics approval and consent to participate}

This study was conducted in accordance with the Tri-Council Policy Statement, "Ethical Conduct for Research Involving Humans" [45]. Ethics approval for the study was obtained from the McMaster University Research and Ethics Board and renewed yearly as required (\# 05-279). All participants provided written informed consent for participation.

\section{Consent for publication}

N/A

\section{Competing interests}

The authors declare that they have no competing interests.

\section{Publisher's Note}

Springer Nature remains neutral with regard to jurisdictional claims in published maps and institutional affiliations.

\section{Author details}

${ }^{1}$ Centre for Excellence in Economic Analysis Research, Li Ka Shing Knowledge Institute, St. Michael's Hospital, 30 Bond Street, Toronto, ON M5B 1W8, Canada. ${ }^{2}$ Institute of Health Policy, Management and Evaluation, University of Toronto, 155 College St, Toronto, ON M5T 3M6, Canada. ${ }^{3}$ School of Nursing; Clinical Epidemiology and Biostatistics, McMaster University, 1200 Main St. W,

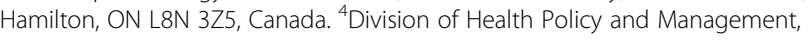
Department of Public Health Sciences, University of California, Davis, 2103 Stockton Blvd. Sacramento, California 95817, USA.
Received: 10 March 2017 Accepted: 24 August 2017

Published online: 01 September 2017

\section{References}

1. Gillespie LD, Robertson MC, Gillespie WJ, Sherrington C, Gates S, Clemson $L M$, et al. Interventions for preventing falls in older people living in the community. The Cochrane database of systematic reviews. 2012;9: CD007146.

2. Gielen AC, McDonald EM, Shields W. Unintentional home injuries across the life span: problems and solutions. Annu Rev Public Health. 2015;36:231-53.

3. Farag I, Howard K, Ferreira ML, Sherrington C. Economic modelling of a public health programme for fall prevention. Age Ageing. 2015;44(3):409-14.

4. Rubenstein LZ. Falls in older people: epidemiology, risk factors and strategies for prevention. Age and ageing. 2006;35(Suppl 2):ii37-41.

5. Fletcher $P$, Berg K, Dalby $D$, Hirdes J. Risk factors for falling among community-based seniors. Journal of Patient Safety. 2009;5(2):61-6.

6. Scuffham P, Chaplin S, Legood R. Incidence and costs of unintentional falls in older people in the United Kingdom. J Epidemiol Community Health. 2003:57(9):740-4.

7. Heinrich S, Rapp K, Rissmann U, Becker C, Konig HH. Cost of falls in old age: a systematic review. Osteoporos Int. 2010;21(6):891-902.

8. Summary of the Updated American Geriatrics Society/British Geriatrics Society Clinical Practice Guideline for Prevention of Falls in Older Persons. Journal of the American Geriatrics Society. 2011;59(1):148-57.

9. Markle-Reid M, Browne G, Gafni A, Roberts J, Weir R, Thabane L, et al. A crosssectional study of the prevalence, correlates, and costs of falls in older home care clients' at risk'for falling. Canadian Journal on Aging. 2010;29(1):119.

10. Karlsson MK, Magnusson H, von Schewelov T, Rosengren BE. Prevention of falls in the elderly-a review. Osteoporos Int. 2013;24(3):747-62.

11. Pfortmueller CA, Lindner $G$, Exadaktylos AK. Reducing fall risk in the elderly: risk factors and fall prevention, a systematic review. Minerva Med. 2014;105(4):275-81.

12. Svantesson U, Babagbemi B, Foster L, Alricsson M. Influences on modern multifactorial falls prevention interventions and fear of falling in non-frail older adults: a literature review. Journal of Clinical Medicine Research. 2014;6(5):314-20.

13. Campbell AJ, Robertson MC. Rethinking individual and community fall prevention strategies: a meta-regression comparing single and multifactorial interventions. Age Ageing. 2007:36(6):656-62.

14. Beard J, Rowell D, Scott D, van Beurden E, Barnett L, Hughes K, et al. Economic analysis of a community-based falls prevention program. Public Health. 2006;120(8):742-51

15. Rizzo JA, Baker DI, McAvay G, Tinetti ME. The cost-effectiveness of a multifactorial targeted prevention program for falls among community elderly persons. Med Care. 1996;34(9):954-69.

16. Carande-Kulis V, Stevens JA, Florence CS, Beattie BL, Arias I. A cost-benefit analysis of three older adult fall prevention interventions. J Saf Res. 2015;52:65-70

17. Wu S, Keeler EB, Rubenstein LZ, Maglione MA, Shekelle PG. A costeffectiveness analysis of a proposed national falls prevention program. Clin Geriatr Med. 2010;26(4):751-66

18. Patil R, Kolu P, Raitanen J, Valvanne J, Kannus P, Karinkanta S, et al. Costeffectiveness of vitamin $D$ supplementation and exercise in preventing injurious falls among older home-dwelling women: findings from an RCT. Osteoporos Int. 2016;27(1):193-201.

19. Poole CD, Smith J, Davies JS. Cost-effectiveness and budget impact of empirical vitamin $D$ therapy on unintentional falls in older adults in the UK. BMJ Open. 2015:5(9):e007910.

20. Hendriks M, Evers S, Bleijlevens M, van Haastregt J, Crebolder H, van Eijk J. Cost-effectiveness of a multidisciplinary fall prevention program in community-dwelling elderly people: a randomized controlled trial. Int J Technol Assess Health Care. 2008;24(2):193-202.

21. Davis J, Robertson MC, Ashe M, Liu-Ambrose T, Khan K, Marra C. Does a home-based strength and balance programme in people aged $>$ or $=80$ years provide the best value for money to prevent falls? A systematic review of economic evaluations of falls prevention intervention. $\mathrm{Br}$ J Sports Med. 2010;44(2):80-9.

22. Jenkyn KB, Hoch JS, Speechley M. How much are we willing to pay to prevent a fall? Cost-effectiveness of a multifactorial falls prevention program for community-dwelling older adults. Canadian Journal on Aging. 2012;31(2):121-37. 
23. Frick KD, Kung JY, Parrish JM, Narrett MJ. Evaluating the cost-effectiveness of fall prevention programs that reduce fall-related hip fractures in older adults. J Am Geriatr Soc. 2010;58(1):136-41.

24. Church J, Goodall S, Norman R, Haas M. The cost-effectiveness of falls prevention interventions for older community-dwelling Australians. Aust N Z J Public Health. 2012;36(3):241-8.

25. Peeters GM, Heymans MW, de Vries OJ, Bouter LM, Lips P, van Tulder MW. Multifactorial evaluation and treatment of persons with a high risk of recurrent falling was not cost-effective. Osteoporos Int. 2011;22(7):2187-96.

26. Irvine L, Conroy S, Sach T, Gladman J, Harwood R, Kendrick D, et al. Cost-effectiveness of a day hospital falls prevention programme for screened community-dwelling older people at high risk of falls. Age Ageing. 2010;39(6):710-6.

27. McLean K, Day L, Dalton A. Economic evaluation of a group-based exercise program for falls prevention among the older community-dwelling population. BMC Geriatr. 2015;15:33.

28. Robertson MC, Gardner MM, Devlin N, McGee R, Campbell AJ. Effectiveness and economic evaluation of a nurse delivered home exercise programme to prevent falls. 2: controlled trial in multiple centres. BMJ. 2001;322(7288):701-4.

29. Church J, Goodall S, Norman R, Haas M. An economic evaluation of community and residential aged care falls prevention strategies in NSW. New South Wales public health bulletin. 2011;22(3-4):60-8.

30. Markle-Reid M, Browne G, Gafni A, Roberts J, Weir R, Thabane L, et al. The effects and costs of a multifactorial and interdisciplinary team approach to falls prevention for older home care clients 'at risk' for falling: a randomized controlled trial. Canadian Journal on Aging. 2010a;29(1):139-61.

31. Registered Nurses' Association of Ontario. Nursing best practice guideline: Prevention of fall injuries in the older adult. Toronto, Ontario, Canada; 2011.

32. Browne G, Gafni A, Roberts J. Approach to the measurement of resource use and costs (working paper S06-01). Hamilton, Ontario, Canada: McMaster University, System-Linked Research Unit on Health and Social Service Utilization; 2006.

33. Browne G, Roberts J, Byrne C, Gafni A, Weir R, Majumdar B. The costs and effects of addressing the needs of vulnerable populations: results of 10 years of research. Can J Nurs Res. 2001:33:65-76.

34. Browne G, Roberts J, Gafni A, Byrne C, Weir R, Majumdar B, et al. Economic evaluations of community-based care: lessons from twelve studies in Ontario. J Eval Clin Pract. 1999:5:367-85.

35. Hoch J, Briggs A, Willan A. Something old, something new, something borrowed, something blue: a framework for the marriage of health econometrics and cost-effectiveness analysis. Health Econ. 2002;11:415-30.

36. Drummond M, Sculpher M, Torrance G, O'Brien B, Stoddart G. Methods for the economic evaluation of health care programmes. 3rd ed. New York: Oxford University Press; 2005.

37. Fenwick E, O'Brien B, Briggs A. Cost-effectiveness acceptability curves facts, fallacies, and frequently asked questions. Health Econ. 2004;13:405-15.

38. Hoch J, Rockx M, Krahn A. Using the net benefit regression framework to construct cost-effectiveness acceptability curves: an example using data from a trial of external loop recorders versus Holter monitoring for ambulatory monitoring of "community acquired" syncope. BMC Health Services Research. 2006;(6)68.

39. Fletcher PC, Hirdes JP. Risk factors for falling among community-based seniors using home care services. J Gerontol Ser A Biol Med Sci. 2002;57(8):M504-M10.

40. Society AG, Society G. American Academy of Orthopaedic Surgeons Panel on Falls Prevention. Guideline for the prevention of falls in older persons. J Am Geriatr Soc. 2001;49(5):664-72.

41. Soriano TA, DeCherrie LV, Thomas DC. Falls in the community-dwelling older adult: a review for primary-care providers. Clin Interv Aging. 2007;2(4):545.

42. Stevens JA. Falls among older adults_risk factors and prevention strategies. J Saf Res. 2005:36(4):409-11.

43. Briggs $\mathrm{AH}, \mathrm{O}$ 'Brien BJ. The death of cost-minimization analysis? Health Econ. 2001;10(2):179-84

44. Gallagher $\mathrm{E}$, Brunt $\mathrm{H}$. Head over heels: impact of a health promotion program to reduce falls in the elderly. Canadian Journal on Aging. 1996;15(1):84-96.

45. Canadian Institutes of Health Research, Natural Sciences and Engineering Research Council of Canada, Social Sciences and Humanities Research Council of Canada. Tri-council policy statement: Ethical conduct for research involving humans. 1998 (with 2000, 2002 and 2005 amendments) [Available from: http:// www.pre.ethics.gc.ca/eng/policy-politique/initiatives/tcps2-eptc2/Default/.

\section{Submit your next manuscript to BioMed Central and we will help you at every step:}

- We accept pre-submission inquiries

- Our selector tool helps you to find the most relevant journal

- We provide round the clock customer support

- Convenient online submission

- Thorough peer review

- Inclusion in PubMed and all major indexing services

- Maximum visibility for your research

Submit your manuscript at www.biomedcentral.com/submit
) Biomed Central 